\title{
CLASS ACTION, UNE ADAPTATION VARIÉE EN FRANÇAIS, EN POLONAIS ET EN TCHĖQUE : REFLETS LINGUISTIQUES
}

\author{
ANNA BOBIŃSKA, JOHN HUMBLEY, RADKA \\ MUDROCHOVÁ', MATÚŠ HANULIAK
}

\begin{abstract}
Class action, variously adapted in French, Polisch and Czech languages: linguistic reflections

The objective of this article is to study the linguistic adaptation that accompanies the introduction and modification of a type of lawsuit originating in another legal system: the case of class action. In the context of the study of the comparative neology of French, Polish and Czech, considered in particular from the angle of borrowing and its equivalents, it is interesting to explore the adoption and linguistic adaptation of a legal concept. The one selected for this study is the American class action, which has already been the subject of a linguistic analysis focusing on French in France and French-speaking countries, and in Spain and Italy. The present study therefore extends the research carried out so far to the cases of Czech and Polish while updating the data on French.
\end{abstract}

Keywords : Neology, terminology, class action, native equivalent, borrowing

Mots-clés : Néologie, terminologie, class action, équivalent autochtone, emprunt

\section{Introduction}

L'objectif de cet article est d'étudier l'adaptation linguistique qui accompagne l'introduction et la modification d'un dispositif originaire d'un autre système juridique : le cas de class action.

Dans le cadre de l'étude de la néologie comparée du français, du polonais et du tchèque, considérée en particulier sous l'angle de l'emprunt et de ses équivalents, il est intéressant d'explorer l'adoption et l'adaptation linguistique d'un concept juridique complexe mais susceptible de concerner tout un chacun. Celui qui est retenu dans le cadre de la présente étude, class action, a déjà fait l'objet d'une analyse linguistique axée sur le français

\footnotetext{
Le présent article s’inscrit dans le Projet Européen du Développement Régional « Créativité et adaptabilité comme conditions du succès de l'Europe dans un monde interconnecté » (No. CZ.02.1.01/0. 0/0.0/16_019/0000734).
} 
de France et des pays francophones, et sur l'Espagne et l'Italie². Si dès 1978 le Québec avait adopté une version de la class action (sous le nom de recours collectif), la France a dû attendre 2014 pour qu'un équivalent (action de groupe) soit intégré et la Pologne 2010 (pozew zbiorowy), tandis que la République tchèque serait sur le point d'inscrire sa propre version dans la législation. Pour des raisons qui seront exposées ci-après, le droit des pays européens ne permet pas d'adopter sans modification la «class action ». L'exemple des pays francophones, de l'Espagne et de l'Italie, illustre une très grande diversité au niveau de l'adaptation linguistique. Dans presque tous les cas l'emprunt direct finit par être réservé soit à un modèle étranger (américain) qu'il est question d'adapter soit à l'évocation de cas concrets de procès menés à l'étranger, généralement aux États-Unis. Le nouveau dispositif juridique est généralement nommé dans la langue autochtone de telle sorte que la dénomination reflète une des spécificités de cette législation locale, comme c'est le cas en Belgique ou au début des années 2000 en Italie (voir infra). L’hypothèse adoptée ici pour le polonais et pour le tchèque est que l'emprunt direct serait réservé au xénisme et que l'adaptation sera nommée en exprimant une des spécificités de la législation nationale. Il reste à savoir d'une part si des différences se manifestent entre le polonais, où une législation nationale existe déjà depuis 2010 et le tchèque, où pour l'heure aucune loi n'a été votée et d'autre part si les préconisations au niveau de l'Union européenne, qui sont exprimées dans toutes les langues de l'UE, dont celles qui nous intéressent, sont suivies par des dénominations au niveau national.

\section{Méthode}

Le corpus utilisé dans cette étude exploratoire est diversifié et en partie aléatoire. Afin de cerner les caractéristiques essentielles des enjeux, les textes européens et les textes de législation nationales ont été consultés. Ces éléments de corpus sont complétés par la consultation de sites indiqués ci-après. Contrairement aux articles précédents, toutefois, la présente étude a été réalisée avec le concours d'un juriste qui est un des coauteurs (M. Hanuliak), ce qui permet un début d'approfondissement de la dimension juridique des termes en question. Afin d'étudier la réception des termes officiels et d'autres, le corpus de langue générale est composé de textes avant tout journalistiques (JSI 2014-2016 et 2014-2020 dans Sketch Engine) pour les trois langues. Pour le français et pour le tchèque, l'étude tiendra compte des corpus exploités pour les articles antérieurs, en particulier Europresse pour le cas du français et Anopress pour le tchèque; le polonais, pour sa part, ne dispose pas d'un corpus comparable.

\footnotetext{
Pour la France voir (Humbley 2017), les pays francophones (Boutmgharine-Idiassner et Humbley 2018), l'Espagne (Boutmgharine-Idiassner et Humbley 2016) et l'Italie (Humbley 2018).
} 


\section{Les modèles juridiques de la class action}

\subsection{Le modèle : la class action à l'américaine}

Avant d'examiner les adaptations, il est utile de connaître en quoi consiste le modèle. Le descriptif qui suit n'a pas l'ambition de synthétiser une question juridique complexe mais tout simplement de fournir des éléments de comparaison entre les deux systèmes juridiques.

Dans son acception la plus générale, aux États-Unis, class action est définie comme " lawsuit in which the court authorizes a single person or a small group of people to represent the interests of a larger group » (Garner 2009). Il s'agirait d'un concept relativement récent, car selon le dictionnaire cité, l'expression ne date que de 1909. Un autre ouvrage classique, A Dictionary of Modern Legal Usage (Garner 1995), définit class action d'une manière plus pertinente comme " a lawsuit instituted by one or more parties on behalf not only of themselves but also of many other parties when common questions of law and fact are involved ».

Par rapport aux droits de la tradition continentale civiliste, elle diffère de plusieurs points de vue :

- Elle contrevient au principe que « nul ne plaide par procureur », c'est-à-dire qu'on n'a pas le droit d'engager une action à la place de quelqu'un d'autre : or, le principe même de la class action est qu'une personne (physique ou morale selon les pays) plaide pour la totalité des individus lésés.

- En outre, elle se heurte aux obstacles liés aux principes fondamentaux de la procédure civile, dont par exemple la litispendance ${ }^{3}$ et l'autorité relative de la chose jugée. ${ }^{4}$

- De même, elle diffère des traditions civilistes, qui n'envisagent pas de dommages et intérêts à titre punitif.

- D'autres aspects caractéristiques du système judiciaire américain ont également été favorables à l'essor des class actions :

- la procédure dite de pre-trial discovery (permettant au demandeur à une action en justice d'accéder à des documents et des informations détenus par le défendeur à l'action qui doit ainsi fournir même les pièces en sa défaveur),

- la présence des jurés populaires même en matière civile (jury trial),

- et, bien sûr, les honoraires de résultat (contingency fee) des avocats (généralement de $20 \%$ à $30 \%$ du résultat de l'affaire).

État d'un litige porté simultanément devant deux tribunaux du même degré, l'un et l'autre compétents pour en connaître, et susceptible de provoquer le dessaisissement de l'un en faveur de l'autre. Dans le contexte du recours collectif, ce principe soulève la question de savoir si une (première) action collective empêche toute autre action (collective et individuelle) postérieure portant sur les faits similaires afin d'éviter les litiges parallèles, avec des résultats potentiellement divergents. La situation se complique davantage dans le cas de recours collectifs transfrontaliers concurrents.

4 Elle désigne l'autorité attachée à un acte juridictionnel, qui en interdit la remise en cause en dehors des voies de recours légalement ouvertes. Traditionnellement, elle s'impose à ceux qui ont été parties ou représentés à l'instance (inter partes). Dans le contexte du recours collectif, il n'est pas évident, si la décision doit lier tous les membres du groupe voire tout le monde (erga omnes). Face au recours collectif, les principes généraux doivent être revus sans que l'on empêche ou entrave l'accès à la justice des particuliers pris isolément. 
Ces éléments sont généralement non-existants dans les ordres juridiques continentaux comme la France, la République tchèque et la Pologne. Bien que la "class action » moderne soit un produit du droit américain fédéral, les traits d'un recours collectif peuvent être discernés dès le droit romain classique. Même si la continuité s'est brisée, le droit civil moderne n'est pas insensible à la protection judiciaire des intérêts collectifs. Seulement, pour des raisons historiques, les moyens juridiques utilisés pour parvenir à cet objectif sont différents. Ainsi, outre le contrôle exercé par les autorités publiques (dont les compétences sont beaucoup plus restreintes aux États-Unis), la protection est-elle accomplie par une action représentative d'un organisme habilité à défendre les intérêts en cause (association, syndicat, ordre professionnel) plutôt que par une action collective. $^{5}$

\subsection{Le niveau de l'Union européenne}

Il existe depuis longtemps au niveau de l'Union européenne une volonté d'harmoniser les pratiques - souvent fort divergentes, dans les différents pays membres. Afin de bien se distinguer des pratiques américaines, les instances de l'Union européenne évitent soigneusement de parler de class action même en anglais, auquel ils préféraient recours collectif en français et collective redress en anglais comme hypéronymes englobant l'ensemble des mécanismes existants et à venir. Une recommandation de $2013^{6}$ préconisait déjà une harmonisation du recours collectif par rapport à la législation sur l'action en cessation ${ }^{7}$, et en 2018 un communiqué de presse annonce « les premières règles européennes sur le recours collectif». ${ }^{8}$ Le rapport, disponible dans toutes les langues de l'Union, contient l'essentiel de la terminologie de l'action de groupe vue dans un contexte juridique européen. ${ }^{9}$ Au niveau des actes normatifs européens, plusieurs directives se sont succédé. ${ }^{10}$ La plus récente date du 25 novembre 2020 et concerne, dans sa version française, les " actions représentatives visant à protéger les intérêts collectifs des consommateurs " et en anglais des « representative actions for the protection of the collective interests of consumers ${ }^{11}$

\footnotetext{
L'intérêt collectif ainsi conçu constitue une finalité en soi, dépassant une simple somme des intérêts individuels.

6 Recommandation de la Commission du 11 juin 2013 relative à des principes communs applicables aux mécanismes de recours collectif en cessation et en réparation dans les États membres en cas de violation de droits conférés par le droit de l'Union (2013/396/UE).

7 Dans le contexte du droit de l'Union, l'action en cessation est une procédure qui permet de faire cesser ou interdire une infraction nuisant aux intérêts collectifs des consommateurs. https://eur-lex.europa.eu/.

8 Vers le tout premier mécanisme de recours collectif de l'UE Communiqué de presse JURI 06-12-2018 13:56 https://www.europarl.europa.eu/news/fr/press-room/20181205IPR21088/vers-le-tout-premier-mecanisme-de-recours-collectif-de-l-ue, consulté le 29. 12. 2020.

9 Proposal for a directive of the european parliament and of the council on representative actions for the protection of the collective interests of consumers, and repealing Directive 2009/22/EC, https:// eur-lex.europa.eu/legal-content/EN/TXT/?uri=CELEX\%3A52018PC0184, consulté le 29. 12. 2020.

10 La directive 98/27/CE du Parlement européen et du Conseil du 19 mai 1998 relative aux actions en cessation en matière de protection des intérêts des consommateurs, remplacée (recodifiée) par la directive 2009/22/CE du Parlement européen et du Conseil du 23 avril 2009.

11 Directive (UE) 2020/1828 du Parlement européen et du Conseil du 25 novembre 2020 relative aux actions représentatives visant à protéger les intérêts collectifs des consommateurs et abrogeant la directive 2009/22/CE.
} 
L’objectif de cette nouvelle législation est « d'améliorer l'efficacité de la procédure d'action en cessation et de contribuer à l'élimination des conséquences des infractions au droit de l'Union qui portent atteinte aux intérêts collectifs des consommateurs ". ${ }^{12}$ Autrement dit, tout en restant limitée à la matière du droit de la consommation, la nouvelle directive complète le dispositif existant (limité aux actions en cessation) par des mécanismes de recours collectif en réparation, adaptés aux situations de préjudice de masse. ${ }^{13}$ D'un point de vue terminologique, il n'est plus question ni de recours collectif ni de collective redress. Le législateur européen opte enfin pour les " actions représentatives ", expression apparemment plus neutre, comme hypéronyme couvrant l'ensemble de ces mécanismes. Se limitant à créer un cadre commun général, il laisse le choix terminologique définitif aux législateurs nationaux, obligés de transposer la directive dans leurs ordres juridiques respectifs.

En étudiant la situation terminologique de class action en République tchèque dans le cadre du droit européen, en nous appuyant notamment sur la traduction des documents officiels de l'Union européenne, nous constatons que la terminologie appliquée et les termes clés utilisés, en particulier dans les titres de la documentation traduite en tchèque, ne sont pas entièrement cohérents.

À titre d'exemple, dans la recommandation de la Commission du 11 juin 2013 relative à des principes communs applicables aux mécanismes de recours collectif en cessation et en réparation dans les États membres en cas de violation de droits conférés par le droit de l'Union (2013/396/UE) de même que dans le rapport de la Commission concernant la mise en œuvre de cette recommandation, le terme privilégié pour le recours collectif („collective redress") dans la version tchèque est celui de kolektivní právní ochrana. Cependant, la traduction tchèque du rapport emploie ${ }^{14} \mathrm{~d}^{\prime}$ autres expressions pour désigner le concept exprimé en anglais par collective redress et en français par recours collectif („collective redress"), à savoir : kolektivní odškodnění (dédommagement collectif), řizení pro kolektivní uplatnění nároků na náhradu škody (procédure du recours collectif pour le dédommagement), kolektivní žaloba/ rízení o kolektivní žalobě (plainte collective/ procédure sur la plainte collective), ce dernier employé notamment dans l'expression spécifiée de "collective redress action» tout comme kolektivní rízení (procédure collective) qui rend „collective redress procedure“. En outre, les textes évoquent la différence entre "collective action“ (dans le texte français : action de groupe) (skupinová žaloba) et "representative action" (dans le texte français : action en représentation) (reprezentativní žaloba) dans la spécification du recours collectif (considérants 17 et 18 de la recommandation de la Commission).

$12 C f$. Proposition de directive du Parlement Européen et du Conseil relative aux actions représentatives dans le domaine de la protection des intérêts collectifs des consommateurs, et abrogeant la directive 2009/22/CE.

13 Pour distinguer le dispositif européen du modèle américain, le législateur européen prend soin de souligner, dès le début, que « [p]our empêcher l'utilisation abusive des actions représentatives, il convient $[\ldots]$ d'éviter des éléments tels que les dommages et intérêts à caractère punitif et l'absence de limitations quant à la qualité pour agir au nom des consommateurs lésés » (cf. considérant 10 de la directive).

14 Au moins dans certains cas, cette différenciation semble être due d'une part au choix du texte d'origine pour la traduction tchèque (probablement l'anglais qui diffère du texte français), d'autre part aux variations contextuelles (par exemple les parties du texte consacrés à l'évaluation des législations nationales). 
En ce qui concerne la tentative d'unification de la terminologie polonaise au niveau de l'UE, l'analyse de la traduction des documents officiels, notamment de la traduction de la proposition de directive du Parlement européen et du Conseil relative aux actions représentatives dans le domaine de la protection des intérêts collectifs des consommateurs, datant de 2018, montre que le polonais met en avant trois termes : premièrement celui de powództwo zbiorowe pour collective action en anglais et ensuite celui de dochodzenie roszczeń w postępowaniu grupowym ou encore celui de zbiorowe dochodzenie roszczeńles deux pour collective redress. Il est intéressant de noter que seule la première proposition de traduction de collective redress est basée sur le terme figurant dans le texte officiel de la loi en droit polonais (à savoir, postępowanie grupowe). Elle est en même temps plus descriptive car elle combine en fait deux termes différents : dochodzenie roszczeń (recours collectif en français) et postępowanie grupowe (action de groupe en français).

Pour aller plus loin, nous avons consulté le concept de « collective redress » dans la base de terminologie IATE, dont les extraits, malheureusement sous forme d'un simple

\begin{tabular}{|c|c|c|c|c|c|}
\hline \multicolumn{6}{|c|}{$\star 3524401$} \\
\hline \multicolumn{4}{|c|}{ LAW (12) } & \multicolumn{2}{|l|}{$\operatorname{coM}$} \\
\hline ten & collective redress & $\star \star \star \star$ & 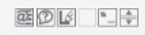 & COM & \\
\hline fr & recours collectif & $\star \star$ & 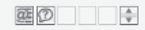 & Council & \\
\hline \multicolumn{5}{|c|}{$\star 782702$} & 2 \\
\hline \multicolumn{3}{|c|}{$\begin{array}{l}\text { LAW (12) } \\
\text { consumption (2026) [TRADE] }\end{array}$} & & Council & \\
\hline \multirow{3}{*}{ en } & collective action & $\star \star \star$ & 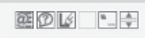 & Council & \\
\hline & Rearrected from: collectlve redress & & & & \\
\hline & collective claim & $\star \star \star \star$ & 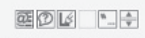 & COM & \\
\hline \multirow[t]{3}{*}{ t. fr } & action collective & $\star \star \star$ & 国回 口田 & Council & \\
\hline & recours collectif & $\star \star \star$ & (D) & Council & \\
\hline & plainte collective & $\star \star \star$ & 예(1) & COM & \\
\hline \multicolumn{5}{|c|}{$\star 3524401$} & 1 \\
\hline \multicolumn{3}{|c|}{ LAW (12) } & & COM & \\
\hline \multicolumn{2}{|r|}{ collective redress } & $\star \star \star \star$ & 国区国 $=0$ & COM & \\
\hline \multirow[t]{2}{*}{$\mathrm{pl}$} & dochodzenie roszczeń w postępowaniu grupowym & $\star \star$ & $\square$ & Council & \\
\hline & zbiorowe dochodzenie roszczeń & $\star \star \star$ & 国(10 & Council & \\
\hline \multicolumn{2}{|c|}{$\star 782702$} & & & & 2 \\
\hline \multicolumn{2}{|c|}{$\begin{array}{l}\text { LAW (12) } \\
\text { consumption (2026) [TRADE] }\end{array}$} & & & Council & \\
\hline \multirow[t]{3}{*}{ en } & collective action & $\star \star \star \star$ & 国D国 $\square: 6$ & Council & \\
\hline & Reairected frornc collective redress & & & & \\
\hline & collective claim & $\star \star \star \star$ & 国区国 $\square 6$ & COM & \\
\hline $\mathrm{pl}$ & powództwo zbiorowe & $\star \star \star *$ & 国( $\quad 96$ & Council & \\
\hline \multicolumn{2}{|c|}{$\star 3524401$} & & & & 1 \\
\hline \multicolumn{2}{|c|}{ LAW (12) } & & & $\mathrm{COM}$ & \\
\hline t.en & collective redress & $\star \star \star$ & 편(이 $\because:$ & COM & \\
\hline cs & hromadná žaloba & $\star \star$ & 펴이녕 & $\mathrm{COM}$ & \\
\hline
\end{tabular}

Figure 1 : Extraits de la base de terminologie $\operatorname{IATE}^{15}$

15 https://iate.europa.eu/search/standard/result/1609343005667/1, consulté le 03. 01. 2021. 
lexique, sont reproduits dans la Figure 1 (consulté le 03. 01. 2021). Tandis que la base contient plusieurs équivalents pour le français et le polonais, le tchèque se limite à un seul terme autochtone, celui de hromadná žaloba.

Dans la traduction du contenu de la directive en question d'autres expressions du phénomène décrit apparaissent aussi. Néanmoins, cette terminologie semble constituer un tout suffisamment cohérent du point de vue linguistique, et par conséquent, efficace en termes de son application au sein du droit communautaire.

Voici à quoi ressemble la gestion de la terminologie appliquée au phénomène en question dans les trois langues étudiées ( $c f$. tableau 1).

Tableau 1 : La terminologie européenne de la class action

\begin{tabular}{|c|c|c|}
\hline $\begin{array}{l}\text { DYREKTYWA } \\
\text { PARLAMENTU } \\
\text { EUROPEJSKIEGO I RADY } \\
\text { w sprawie powództw } \\
\text { przedstawicielskich w celu } \\
\text { ochrony zbiorowych interesów } \\
\text { konsumentów i uchylająca } \\
\text { dyrektywę 2009/22/WE }\end{array}$ & $\begin{array}{l}\text { DIRECTIVE DU } \\
\text { PARLEMENT EUROPÉEN } \\
\text { ET DU CONSEIL relative aux } \\
\text { actions représentatives dans } \\
\text { le domaine de la protection } \\
\text { des intérêts collectifs des } \\
\text { consommateurs, et abrogeant } \\
\text { la directive } 2009 / 22 / \mathrm{CE}\end{array}$ & $\begin{array}{l}\text { SMĚRNICE EVROPSKÉHO } \\
\text { PARLAMENTU A RADY } \\
\text { o zástupných žalobách } \\
\text { na ochranu kolektivních } \\
\text { zájmů spotřebitelů a o zrušení } \\
\text { směrnice } 2009 / 22 / E S\end{array}$ \\
\hline $\begin{array}{l}\text { powództwo zbiorowe } \\
\text { pozew zbiorowy } \\
\text { zbiorowe dochodzenie roszczeń }\end{array}$ & action collective & kolektivní žaloba \\
\hline $\begin{array}{l}\text { powództwo zbiorowe } \\
\text { pozew zbiorowy } \\
\text { zbiorowe dochodzenie roszczeń } \\
\text { zbiorowe postępowania sądowe }\end{array}$ & action collective en justice & kolektivní žaloba \\
\hline zbiorowe działania następcze & action collective de suivi & kolektivní navazující žaloba \\
\hline $\begin{array}{l}\text { zbiorowe dochodzenia środków } \\
\text { naprawczych }\end{array}$ & $\begin{array}{l}\text { actions collectives en } \\
\text { réparation }\end{array}$ & $\begin{array}{l}\text { kolektivní žaloby na vydání } \\
\text { opatření ke zjednání nápravy }\end{array}$ \\
\hline pozew zbiorowy & action de groupe & skupinová žaloba \\
\hline $\begin{array}{l}\text { nakaz zaprzestania szkodliwych } \\
\text { praktyk }\end{array}$ & action en cessation & žaloba na zdržení se jednání \\
\hline $\begin{array}{l}\text { zbiorowe powództwo } \\
\text { o odszkodowanie }\end{array}$ & $\begin{array}{l}\text { action en dommages et intérêts } \\
\text { sous la forme d'un recours } \\
\text { collectif }\end{array}$ & $\begin{array}{l}\text { kolektivní žaloba na náhradu } \\
\text { škody }\end{array}$ \\
\hline powództwo przedstawicielskie & action en représentation & reprezentativní žaloba \\
\hline powództwa przedstawicielskie & actions représentatives & zástupné žaloby \\
\hline $\begin{array}{l}\text { krajowe powództwo } \\
\text { przedstawicielskie }\end{array}$ & action représentative nationale & vnitrostátní zástupná žaloba \\
\hline $\begin{array}{l}\text { transgraniczne powództwo } \\
\text { przedstawicielskie }\end{array}$ & $\begin{array}{l}\text { action représentative } \\
\text { transfrontière }\end{array}$ & přeshraniční zástupná žaloba \\
\hline $\begin{array}{l}\text { powództwa przedstawicielskie } \\
\text { w sprawie środków } \\
\text { nakazujących zaprzestanie } \\
\text { szkodliwych praktyk }\end{array}$ & $\begin{array}{l}\text { actions représentatives visant } \\
\text { à obtenir des mesures de } \\
\text { cessation }\end{array}$ & $\begin{array}{l}\text { zástupné žaloby na vydání } \\
\text { opatření na zdržení se jednání }\end{array}$ \\
\hline
\end{tabular}




\begin{tabular}{|c|c|c|}
\hline $\begin{array}{l}\text { DYREKTYWA } \\
\text { PARLAMENTU } \\
\text { EUROPEJSKIEGO I RADY } \\
\text { w sprawie powództw } \\
\text { przedstawicielskich w celu } \\
\text { ochrony zbiorowych interesów } \\
\text { konsumentów i uchylająca } \\
\text { dyrektywę 2009/22/WE }\end{array}$ & $\begin{array}{l}\text { DIRECTIVE DU } \\
\text { PARLEMENT EUROPÉEN } \\
\text { ET DU CONSEIL relative aux } \\
\text { actions représentatives dans } \\
\text { le domaine de la protection } \\
\text { des intérêts collectifs des } \\
\text { consommateurs, et abrogeant } \\
\text { la directive 2009/22/CE }\end{array}$ & $\begin{array}{l}\text { SMĚRNICE EVROPSKÉHO } \\
\text { PARLAMENTU A RADY } \\
\text { o zástupných žalobách } \\
\text { na ochranu kolektivních } \\
\text { zájmů spotřebitelů a o zrušení } \\
\text { směrnice } 2009 / 22 / \text { ES }\end{array}$ \\
\hline $\begin{array}{l}\text { powództwa przedstawicielskie } \\
\text { w sprawie środków } \\
\text { naprawczych }\end{array}$ & $\begin{array}{l}\text { actions représentatives visant } \\
\text { à obtenir des mesures de } \\
\text { réparation }\end{array}$ & $\begin{array}{l}\text { zástupné žaloby na vydání } \\
\text { opatření ke zjednání nápravy }\end{array}$ \\
\hline $\begin{array}{l}\text { powództwa przedstawicielskie } \\
\text { z myślą o ochronie zbiorowych } \\
\text { interesów (konsumentów) }\end{array}$ & $\begin{array}{l}\text { actions représentatives visant } \\
\text { à protéger les intérêts collectifs } \\
\text { (des consommateurs) }\end{array}$ & $\begin{array}{l}\text { zástupné žaloby na ochranu } \\
\text { kolektivních zájmů } \\
\text { (spotřebitelů) }\end{array}$ \\
\hline $\begin{array}{l}\text { dochodzenie roszczeń w drodze } \\
\text { powództw przedstawicielskich }\end{array}$ & $\begin{array}{l}\text { (chercher à obtenir) réparation } \\
\text { par des actions représentatives }\end{array}$ & $\begin{array}{l}\text { (domáhat se) nápravného } \\
\text { prostředku prostřednictvím } \\
\text { zástupných žalob }\end{array}$ \\
\hline $\begin{array}{l}\text { nakaz zaprzestania szkodliwych } \\
\text { praktyk }\end{array}$ & injonction de cessation & př́ikaz ke zdržení se jednání \\
\hline $\begin{array}{l}\text { wydanie nakazu } \\
\text { wydanie nakazu zaprzestania } \\
\text { szkodliwych praktyk }\end{array}$ & mesures d'injonction & zdržovací žaloby \\
\hline wniosek o wydanie nakazu & $\begin{array}{l}\text { demande d'ordonnance } \\
\text { d'injonction }\end{array}$ & návrh na soudní zákaz \\
\hline $\begin{array}{l}\text { środki zbiorowego dochodzenia } \\
\text { roszczeń (o zaprzestanie } \\
\text { bezprawnych praktyk oraz } \\
\text { roszczeń odszkodowawczych) }\end{array}$ & $\begin{array}{l}\text { mesures (de cessation/ } \\
\text { réparation) collectives }\end{array}$ & $\begin{array}{l}\text { kolektivní opatření (na zdržení } \\
\text { se jednání/ke zjednání nápravy) }\end{array}$ \\
\hline powództwa zbiorowe & plaintes collectives & kolektivní žaloby \\
\hline $\begin{array}{l}\text { roszczenia zbiorowe } \\
\text { zbiorowe dochodzenie roszczeń }\end{array}$ & recours collectif & $\begin{array}{l}\text { hromadná žaloba } \\
\text { kolektivní žaloba }\end{array}$ \\
\hline $\begin{array}{l}\text { roszczenia zbiorowe } \\
\text { (konsumentów) }\end{array}$ & $\begin{array}{l}\text { recours collectifs (pour les } \\
\text { consommateurs) }\end{array}$ & $\begin{array}{l}\text { kolektivní odškodnění } \\
\text { (spotřebitelů) }\end{array}$ \\
\hline $\begin{array}{l}\text { zbiorowe dochodzenie roszczeń } \\
\text { o zaprzestanie bezprawnych } \\
\text { praktyk }\end{array}$ & recours collectif en cessation & $\begin{array}{l}\text { prostředky kolektivní právní } \\
\text { ochrany týkající se zdržení se } \\
\text { jednání }\end{array}$ \\
\hline $\begin{array}{l}\text { zbiorowe dochodzenie roszczeń } \\
\text { odszkodowawczych }\end{array}$ & recours collectif en réparation & $\begin{array}{l}\text { žaloba na kolektivní náhradu } \\
\text { škody }\end{array}$ \\
\hline pozew zbiorowy & recours collectif judiciaire & kolektivní soudní ochrana \\
\hline $\begin{array}{l}\text { (mechanizmy) zbiorowego } \\
\text { dochodzenia roszczeń }\end{array}$ & $\begin{array}{l}\text { (mécanismes de) recours } \\
\text { collectif }\end{array}$ & $\begin{array}{l}\text { (prostředky/mechanismy) } \\
\text { kolektivní právní ochrany }\end{array}$ \\
\hline $\begin{array}{l}\text { (postępowania, przepisy } \\
\text { proceduralne) zbiorowego } \\
\text { dochodzenia roszczeń }\end{array}$ & $\begin{array}{l}\text { (procédures de) recours } \\
\text { collectif }\end{array}$ & $\begin{array}{l}\text { (prostředky) kolektivní právní } \\
\text { ochrany } \\
\text { kolektivní řízení }\end{array}$ \\
\hline nadużywanie drogi sądowej & recours abusifs & zneužívání soudních sporů \\
\hline
\end{tabular}




\subsection{Paramètres de l'adaptation constatés pour les droits déjà étudiés}

Il n'est pas inutile, avant de procéder à l'analyse des données nationales polonaises et tchèques, de faire succinctement le bilan de l'implantation terminologique de ce concept et de ses dérivés dans les pays déjà étudiés. Deux extrémités se démarquent : le Québec ${ }^{16}$, où l'implantation d'une seule forme autochtone (recours collectif) s'est imposée jusque récemment et l'Italie, où c'est l'emprunt direct de l'anglais qui règne sans partage dans la presse et sous forme de calque au niveau officiel («azione collettiva »). Plusieurs facteurs peuvent être invoqués pour expliquer cette différence. Il convient de signaler d'abord un très important décalage de calendrier : au Québec le dispositif est effectivement incorporé dès 1978 dans le Code de procédure civile. Le parlement italien n’a pas tardé à se saisir de la question, mais les discussions ont duré plus de dix ans : dès 1998 une proposition de dédommagement collectif est envisagée, dont une version est incorporée dans le Code de consommation sous le nom bien motivé de "azione collettiva risarcitoria " (action collective de dédommagement), comparable à la dénomination belge de 2014 (action en réparation collective), mais il est remplacé en 2010 par un nouveau dispositif nommé «azione collettiva.»

Un deuxième facteur doit être pris en compte, à savoir l'efficacité du dispositif juridique. Au Québec le recours collectif n'a cessé de fonctionner à la satisfaction générale ${ }^{17}$. En Italie en revanche il s'est révélé très difficile à mettre en œuvre : un article de presse de 2015 fait état de cinquante actions de groupe intentées depuis 2010, aboutissant à un seul dédommagement.

Un troisième facteur qui a certainement joué un rôle est la coordination des politiques législatives et linguistiques : la présence et l'intervention d'une instance de politique linguistique. L'Office québécois de la langue française a promu le terme des législateurs et l'emprunt est totalement absent de la presse québécoise. En Italie, en l'absence d'autorité de politique linguistique et compte tenu du statut officieux de l'anglais qui sert à étiqueter les innovations législatives (Jobs act, fair price, etc.) l'emprunt direct s'est imposé dans la plupart des contextes, surtout journalistiques. Les autres pays étudiés précédemment se placent entre ces deux extrêmes. Le législateur espagnol a trouvé le moyen de faire adopter le dispositif sans le nommer de manière spécifique, tandis qu'en France le chemin de l'adoption a été encore plus long qu'en Italie, puisqu'il a débuté en 1992 sous le nom d'action en représentation conjointe, initiative intéressante mais qui s'est révélée inapplicable. Après bien d'hésitations sous plusieurs gouvernements, une législation créant l'action de groupe est actée en 2014 dans le cadre de la protection du consommateur. À peine moins restrictive que son cousin italien, l'action de groupe à la française n'a guère tenu ses promesses non plus. Inscrit dans le cadre de la protection du consommateur, le dispositif de 2014 s'est révélé trop restrictif et il a fallu légiférer de nouveau pour couvrir les besoins notamment en matière de produits de santé par l'article 184 de la loi du

16 Le Québec est la seule province canadienne où le droit civil a cours.

1718 cas dans la première moitié de 2015, traitant de la concurrence, de la responsabilité extracontractuelle, de la protection du consommateur, de l'environnement, et d'autres encore) http://services. justice.gouv.qc.ca/dgsj/rrc/DemandeRecours/DemandeRecoursRecherche.aspx, consulté le 29. 12. 2020. 
26 janvier 2016 de modernisation du système de santé. La loi du 18 novembre 2016 « de modernisation de la justice du XXIe siècle » introduit une action de groupe générale ${ }^{18}$ en matière civile dont le champ d'application s'étend également à la lutte contre les discriminations, aux questions environnementales et à la protection des données personnelles, et fixe un cadre procédural commun à son exercice. Les législations distinctes ont ainsi fini par être codifiées et le nom d'action de groupe retenu pour toutes les applications. ${ }^{19}$

Pour la France on constate par ailleurs, comme pour le Québec, un consensus entre les autorités législatives et linguistiques : action de groupe est soutenu par le Dispositif d'enrichissement de la langue française, qui le recommande depuis 2006, soit bien avant que la loi ne soit entrée en vigueur.

Compte tenu de la très longue période pendant laquelle l'action de groupe a été en discussion en France - on en trouve des traces dès les années 1980 - il n'est pas étonnant de constater que la synonymie relevée dans la presse est foisonnante : on compte une vingtaine de dénominations en français attestées dans la base Europresse. La présente étude nous permet par ailleurs de mettre à jour l'état des lieux qui date de 2015 et de déterminer si la synonymie se maintient encore à ce très haut niveau.

\section{Class action : son adaptation dans les milieux français, francophones, polonais et tchèque}

La présente étude se focalise sur les moyens linguistiques mis en œuvre dans les trois langues retenues pour désigner le dispositif correspondant du moins en partie à la «class action » américaine. Les enquêtes antérieures ont montré une très grande divergence au niveau du choix de dénomination, allant d'une stratégie d'évitement, constatée pour le législateur espagnol (Boutmgharine-Idiassner et Humbley 2016), qui ne nomme pas spécifiquement le dispositif, à un calque direct de l'anglais et l'emploi officieux mais fréquent de l'emprunt direct en Italie, où l' " azione collettiva » est en réalité bien plus proche de l'action de groupe français que du modèle américain. Il serait donc possible de limiter l'analyse à des textes officiels provenant des législateurs nationaux et européens, avec éventuellement une ouverture vers les écrits juridiques (de doctrine). L’objectif du présent projet, toutefois, est de pister l'évolution des langues en question et de ce point de vue-là il est indispensable de tenir compte également de la réception de ces néologismes par les francophones, les polonophones et les tchécophones en particulier telle qu' elle est reflétée dans la presse des pays concernés. C'est pour cette raison qu'a été retenu le même type de corpus que pour le projet en général, à savoir la presse générale et spécialisée

18 Selon l'article 62 de la loi n 2016-1547 du 18 novembre 2016 « lorsque plusieurs personnes placées dans une situation similaire subissent un dommage causé par une même personne, ayant pour cause commune un manquement de même nature à ses obligations légales ou contractuelles, une action de groupe peut être exercée en justice au vu des cas individuels présentés par le demandeur. Cette action peut être exercée en vue soit de la cessation du manquement mentionné au premier alinéa, soit de l'engagement de la responsabilité de la personne ayant causé le dommage afin d'obtenir la réparation des préjudices subis, soit de ces deux fins. »

19 En droit de la consommation, un modèle spécial d'action de groupe subsiste (parallèlement à l'action exercée dans l'intérêt collectif des consommateurs et l'action en représentation conjointe [déjà mentionnée] plus anciennes). Ainsi, en droit français, coexistent deux modèles distincts d'action de groupe, désignés néanmoins par le même terme. 
(mais non juridique) dans Néoveille et JSI Timestamped à partir de 2014 dans Sketch Engine pour la période la plus récente. Cette partie du corpus sera nécessairement moins fiable juridiquement que les textes législatifs ou de doctrine, mais elle reflètera l'usage constaté des publics concernés.

\subsection{La France et les pays francophones}

En France, malgré la date récente de l'adoption de l'action de groupe, la notion d'une action collective en justice n'est pas inconnue : la loi du 21 mars 1884 relative à la création des syndicats professionnels a permis aux syndicats « de se porter partie civile relativement aux faits portant un préjudice direct ou indirect à l'intérêt collectif de la profession qu'ils représentent $»{ }^{20}$ En conformité avec ce raisonnement, la loi Royer de 1973 a reconnu aux associations agréées de consommateurs une action civile dans " l'intérêt collectif » des consommateurs. Il a fallu attendre la loi Hamon de 2014 pour qu'en France plusieurs personnes placées dans une situation similaire, ayant subi le même dommage causé par une même personne, puissent enfin revendiquer la cessation des pratiques illicites voire la réparation de leur préjudice non par des actions individuelles mais une (seule) action de groupe. La consécration du dispositif, nommé action de groupe, présente - au moins en théorie des avantages indiscutables : favoriser l'accès à la justice même aux particuliers (notamment les consommateurs) dont le préjudice serait trop faible pour être porté en justice d'une manière individuelle et, par ricochet, cultiver le marché et stimuler la concurrence.

En Belgique, l'évolution était semblable, et - sauf dérogations légales expresses ${ }^{21}-$ les juridictions suivaient le principe de "l'intérêt direct et personnel ", déclarant irrecevables les actions intentées par les groupements privés au titre du préjudice subi par leurs membres. En 2014, à la suite de la recommandation de la Commission européenne, "l'action en réparation collective " est introduite dans le Code de droit économique belge, visant uniquement la protection des consommateurs lésés, à titre individuel, par violation par une entreprise de ses obligations contractuelles ou des dispositions légales ou réglementaires spécifiques. À partir de 2018, le mécanisme a été étendu à la protection des petites et moyennes entreprises (PME), « lésées par une cause commune ». Au niveau de la dénomination, on note la présence de réparation, car il ne s'agit pas de dommages et intérêts à titre punitif. Le législateur belge a donc choisi de marquer expressément une différence par rapport à la « class action » à l'américaine.

\subsubsection{Le français : une mise à jour}

Les études précédentes sur l'adaptation de la « class action » en France (Humbley 2017 et Boutmgharine et Humbley 2018) montrent une lente acceptation de la dénomination française officielle (action de groupe) dans la presse, mais en même temps la persistance

20 Ce droit a été reconnu par l'arrêt des Chambres réunies de la Cour de cassation du 5 avril 1913. La formulation a été, par la suite, reprise par le législateur dès 1920, devenue aujourd'hui l'article L. 2132-3 du Code du travail.

21 En Belgique, sont ainsi autorisées à agir en justice les unions professionnelles reconnues de même que les organisations représentatives des travailleurs et des employeurs. Plus récemment, les exceptions légales ont été étendues à la protection du consommateur, à la protection contre le racisme et la xénophobie de même qu'à la protection de l'environnement. 
de l'anglicisme à la fois comme xénisme, mais aussi comme modèle ou repoussoir pour le français. Elles n'ont pu tenir compte de la coordination au niveau ministériel français entre les différents secteurs, mentionnée en 2.3, où l'action de groupe avait un rôle à jouer, après avoir été cantonné dans le domaine de la consommation.

Le tableau 2 plus bas montre l'évolution des attestations de class action et des différents équivalents ou concepts proches dans trois corpus de presse. Le premier, tiré d'Europresse (Humbley 2017), dans la colonne de gauche, donne les résultats d'une requête opérée dans cette base journalistique cumulative qui relève les occurrences dans la presse francophone sur la période d'une vingtaine d'années. Il permet de se rendre compte du foisonnement des équivalents ou des concepts proches employés pendant cette période. Les deuxième et troisième corpus sont limités aux années JSI web corpus 2014-2016 pour la colonne du milieu et 2014-2020 pour l'autre et permet une actualisation des proportions et donc de donner un reflet de la situation aujourd'hui.

Tableau 2 : Relevés de class action et ses équivalents français dans trois corpus

\begin{tabular}{|c|c|c|c|}
\hline & $\begin{array}{c}2015 \\
\text { Europresse }\end{array}$ & $\begin{array}{l}\text { Timestamped } \\
\text { JSI web corpus } \\
2014-2016\end{array}$ & $\begin{array}{c}\text { Timestamped JSI web } \\
\text { corpus 2014-2020 }\end{array}$ \\
\hline Class action & 1338 & 1112 & 2211 \\
\hline (action collective) & 3015 & 3347 & 14406 \\
\hline Action de groupe & 947 & 1743 & 3677 \\
\hline Procédure collective & 592 & 308 & 992 \\
\hline Plainte collective & 388 & 250 & 903 \\
\hline Plainte en nom collectif & 348 & 159 & 314 \\
\hline Recours collectif & 236 & 4240 & 9324 \\
\hline Action populaire & 216 & 457 & 1168 \\
\hline Action de masse & 158 & 81 & 249 \\
\hline Procès collectif & 123 & 73 & 221 \\
\hline Action catégorielle & 48 & 0 & 1 \\
\hline Action en représentation conjointe & 34 & 0 & 1 \\
\hline Action groupée & 33 & 45 & 144 \\
\hline Recours collectif en justice & 19 & 0 & 63 \\
\hline Action judiciaire collective & 18 & 11 & 32 \\
\hline $\begin{array}{l}\text { Action de groupe de/des } \\
\text { consommateurs }\end{array}$ & 6 & 5 & $\begin{array}{c}6 \text { (pour de } \\
\text { consommateurs) } \\
3 \text { (pour des } \\
\text { consommateurs) }\end{array}$ \\
\hline Recours en justice collectif & 2 & 2 & 6 \\
\hline Assignation collective & 1 & (1) & 3 \\
\hline Action collective en justice & 37 & 51 & 200 \\
\hline Action en justice collective & 87 & 18 & 50 \\
\hline
\end{tabular}


Il convient toutefois de signaler l'ambiguïté de la plupart des termes retenus : action collective n'est pas nécessairement un équivalent de class action (on le relève souvent dans la presse sportive avec un tout autre sens), et compte tenu du grand nombre d'occurrences il n'a pas été possible de faire le tri.

Une analyse des différences entre le premier corpus (cumulatif) et les deuxième et troisième (ponctuel au moment où le terme " action de groupe » devient officiel) fait ressortir une consolidation de la terminologie. Le terme juridique action de groupe s'est imposé et dépasse de loin la fréquence de l'emprunt direct, class action. La plupart des supposés équivalents sont moins fréquents en 2014/16 : procédure collective, plainte collective, plainte en nom collectif, etc. tout en accusant une fréquence non négligeable, mais qui ne renvoient pas nécessairement à la notion juridique qui nous intéresse ici.

La grande surprise est taux phénoménal de recours collectif: quatre fois plus qu'action de groupe. On sait que le corpus JSI n' est pas limité à la France, que recours collectif est la dénomination québécoise jusqu'en 2014 et qu'il continue d'être utilisé et que le même terme est employé au niveau européen pour éviter la confusion avec la version américaine, mais plus de 9000 occurrences entre 2014 et 2020 est malgré tout étonnant et reflète sans doute la composition du corpus en question.

Afin de comparer les résultats obtenus dans les corpus constitués, nous avons vérifié dans les archives du Monde les fréquences des termes cités ci-dessus pendant la période commençant le premier janvier 2017.

Les résultats sont également surprenants : 33 articles comportent la mention class action, 15 articles mentionnent action (s) de groupe et seuls 5 recours collectif(s). Il serait toutefois prématuré de conclure que l'emprunt direct ait pris le dessus sur le terme officiel, car des 33 articles, 23 se déroulent aux États-Unis ou concernent le droit américain. Seuls 7 sont situés en France, généralement accompagnés du terme officiel. Il subsiste deux cas douteux, dont un qui concerne l'Europe.

Une certaine hésitation est due au traitement séparé des différents aspects de l'action de groupe, ce qui a amené les journalistes à se référer au modèle américain, plutôt qu'aux efforts éparpillés des Français. Dans (1fr), il s'agit de l'initiative des responsables du Ministère de la Santé d'introduire un dispositif qui serait plus englobant que l'action de groupe, limité aux consommateurs et plus proche, de ce point de vue, à la législation américaine :

(1fr) Des actions de groupe : La loi marque des avancées en prévention, sur l'accès aux soins, les droits des malades... Principale mesure, l'action de groupe, sur le modèle des class actions à l'américaine, donne la possibilité aux patients qui s'estiment victimes de médicaments d'être défendus collectivement devant les tribunaux. Elle a été utilisée pour la première fois le 13 décembre par des mères ayant reçu pendant leur grossesse des antiépileptiques à base d'acide valproïque (affaire de la Dépakine). Le Monde 30. 01. 2017.

Comme pour l'italien, on évoque les déceptions de la législation, qui se révèle d'une application très difficile, comme le témoigne le titre suivant :

(2fr) Le flop des « class actions » à la française, [titre] Le Monde 16. 02. 2018. 


\subsubsection{Reflet lexicographique}

Une analyse de la réception lexicographique de class action et de ses équivalents figure dans Humbley (2017). Ici il sera uniquement question de Wikipédia. L'encyclopédie collaborative est souvent en avance sur la présentation d'innovations (voir rootkit plus bas), mais dans le cas de sa version française, l'explication du dispositif qui nous concerne n'est pas d'une parfaite limpidité et cela pour des questions de terminologie.

Si l'on entre class action dans la boîte de dialogue de Wikipédia française on est dirigé sur une page de désambiguïsation, qui précise que «Class action est une expression anglophone désignant un recours collectif ». Ce dernier lien mène à une page intitulée Action collective (droit), où on relève la définition suivante :

(3fr) Une action collective, une action de groupe ou un recours collectif (« class action » en anglais) est une action en justice ou une procédure qui permet à un grand nombre de personnes, souvent des consommateurs, de poursuivre une personne, souvent une entreprise ou une institution publique, afin d'obtenir une indemnisation financière.

L'article comporte la description "par pays », mais pour la France, c'est un lien qui est proposé «Article détaillé : Action collective en droit français » ${ }^{22}$.

Cette page ne donne pas de définition. À la place, on propose au lecteur ce développement :

(4fr) L'action collective est possible en droit français depuis le 1er octobre 2014, après un long processus d'études et de débats regroupant parlementaires, universitaires et associations.

Mention est faite de la proposition du dispositif d'enrichissement de la langue français (action de groupe) mais c'est seulement à partir de l'interlinéaire ([...] « l'action de groupe introduite en droit français en $2014 »$ ) que le terme officiel est employé, et encore, en codistribution avec recours collectif.

(5fr) Au fil des années, le législateur a progressivement élargi la liste de ces infractions pouvant donner lieu à un recours collectif.

Le foisonnement synonymique que l'on constate dans la presse est reflété dans les articles de Wikipédia, ce qui ne facilite pas la compréhension. Il est permis de penser que l'organisation collective de Wikipédia ne permet pas un contrôle de qualité globale.

Wiktionnaire, en revanche, a une entrée action de groupe et donne comme équivalent anglais class action. La question de la présentation de ces concepts juridiques à un large public mérite réflexion : visiblement il reste du chemin à faire.

22 https://fr.wikipedia.org/wiki/Action_collective_en_droit_fran\%C3\%A7ais, consulté le 05. 01. 2021. 


\subsection{La Pologne et le polonais}

En droit polonais l'équivalent le plus proche de class action, pozew zbiorowy, autrement dit postępowanie grupowe, est une forme d'action conjointe en justice qui réglemente les procédures civiles et qui concerne principalement le droit de la consommation. Cette action collective a été introduite par la loi du 17 décembre 2009 relative à la demande d'indemnisation dans les procédures de groupe (Dz. U. 2010 r. Nr 7, poz. 44). La loi est entrée en vigueur six mois après sa publication, soit le 19 juillet 2010 et, jusqu'à présent, a été modifiée deux fois : d'abord par la loi du 7 avril 2017 apportant un changement dans la définition de certains actes afin de faciliter le recouvrement de créances, et puis par la loi du 4 juillet $2019^{23}$.

En matière juridique, vues dans ses grandes lignes, les procédures de groupe sont proches de l'action de groupe française car elles sont recevables pour les réclamations d'un seul type, poursuivies par au moins 10 personnes (plutôt que par une association, comme en France). Les réclamations doivent être fondées sur la même base factuelle. De plus, et encore comme pour la France, les recours collectifs ne sont possibles que dans les cas concernant la protection des consommateurs, en matière de responsabilité pour un produit dangereux et en responsabilité délictuelle, à l'exception des réclamations pour la protection des droits de la personne. En outre, les individus doivent être représentés par un avocat ou un conseiller juridique dont la rémunération reste réglementée (afin d'éviter les honoraires de résultat mentionnés en 2.1). Quant au montant de la demande de chaque membre du groupe, il doit être normalisé. L'unification du montant des réclamations peut avoir lieu en sous-groupes d'au moins deux personnes. Finalement, le recours collectif est intenté par un représentant du groupe ${ }^{24}$.

Selon les commentaires dans la presse spécialisée polonaise, l'objectif principal des procédures de groupe est d'améliorer l'administration de la justice, de réduire les coûts et d'unifier la jurisprudence dans des affaires identiques. Toutefois, ces procédures ne peuvent couvrir que les réclamations des personnes qui y consentent expressément (opt-in), comme en France.

Contrairement aux suppositions formulées avant l'examen du corpus, on constate qu'aucun article juridique qui décrit la procédure en question, ni celui de Wikipédia polonaise ni le texte de l'acte officiel, ne cite un quelconque modèle étranger et l'emprunt class action n'y figure pas. Le texte de la loi du 17 décembre 2009 oscille entre deux dénominations, pozew zbiorowy et postępowanie grupowe, qui sont utilisées comme synonymes. L'article de Gazeta Prawna évoque également la dénomination grupowe roszczenia.

23 Le texte actuel de la loi est disponible ici : http://isap.sejm.gov.pl/isap.nsf/DocDetails.xsp?id $=$ WDU20100070044\&type $=2$, consulté le 05. 01.2021.

24 Pour en savoir plus, voir :

https://classaction.pl/, consulté le 23. 12. 2020.http://isap.sejm.gov.pl/isap.nsf/DocDetails. xsp?id=WDU20100070044, consulté le 23. 12. 2020.

https://www.infor.pl/prawo/w-sadzie/pozew-zbiorowy/236522,Wymogi-pozwu-zbiorowego.html, consulté le 23. 12. 2020.

https://www.infor.pl/prawo/w-sadzie/postepowanie-sadowe/236468,Jak-przebiega-postepowanie -grupowe.html.

https://pl.wikipedia.org/wiki/Pozew_zbiorowy, consulté le 23. 12. 2020.

https://prawo.gazetaprawna.pl/artykuly/7451, grupowe-roszczenia-w-polskim-prawie-za-i-przeciw .html, consulté le 23. 12. 2020. 
L'examen de l'entrée polonaise de Wikipédia permet de constater que cet article semble privilégier la notion de pozew zbiorowy pour la description du phénomène présenté. Néanmoins, l'existence d'un autre terme, celui de postępowanie grupowe, est aussi mentionnée.

Il convient également de noter que l'emprunt existe dans le nom du portail dédié à l'explication des mécanismes de recours collectifs en Pologne et dans le monde, à savoir ClassAction.pl. Il est aussi utilisé dans la description des procédures juridiques étrangères, autres que polonaises.

\subsubsection{Class action dans les corpus de presse polonaise}

Le corpus Polish web 2012, qui couvre la période de l'adoption de la législation polonaise introduisant le pozew zbiorowy fait état de 115 occurrences de class action et 10 de classaction (en réalité on relève également des formes soudées dans la première liste), que nous avons répartis sommairement en contextes américains, polonais, européens, et autres, dont la nature est difficile à définir. ( $c f$. tableau 3 ).

Tableau 3 : Contextes dans le corpus polonais 2012

\begin{tabular}{|l|c|}
\hline \multicolumn{1}{|c|}{ Pays concerné } & Nombre de contextes \\
\hline Amérique & 57 \\
\hline Pologne & 14 \\
\hline International/Europe & 14 \\
\hline Indéterminé & 30 \\
\hline
\end{tabular}

Il n'est pas sans surprise de constater que la majorité de contextes comportant class action (ou classaction) sont situés aux États-Unis. Compte tenu de la mondialisation, il s'agit souvent de répercussions de produits utilisés en Pologne, comme dans le contexte suivant :

(1pl) USA: pozwy w sprawie rootkita Sony. W Los Angeles (California) złożono pozew zbiorowy (classaction lawsuit) przeciwko Sony. Chodzi o narażenie na szkody użytkowników wypuszczonej na tamtejszy rynek serii płyt CD, które przy okazji instalowały w systemach użytkowników niebezpieczny dla nich mechanizm DRM (w mniemaniu firmy mający chronić jej prawa własności intelektualnej, w rzeczywistości stanowiący dziurę bezpieczeństwa) ${ }^{25}$.

[États-Unis : actions en justice contre les rootkits de Sony. À Los Angeles (Californie), une action collective (classaction lawsuit) a été intentée contre Sony. Il s'agit de l'exposition au préjudice des utilisateurs d'une série de CD commercialisés sur le marché local, qui, par ailleurs, installaient sur les systèmes des utilisateurs un dangereux mécanisme DRM (selon l'entreprise, destiné à protéger ses droits de propriété intellectuelle, mais constituant en réalité une faille de sécurité)]

25 vagla.pl. 
Dans l'extrait $1(1 \mathrm{pl})$, il s'agit d'un procès qui se déroule aux États-Unis mais qui concerne les dispositifs installés dans les produits Sony ${ }^{26}$, avec des répercussions éventuelles dans le monde entier, dont la Pologne.

Parfois on emploie l'emprunt direct lorsqu'il s'agit d'un pays tiers, comme dans l'extrait 2, où il s'agit de l'Italie qui introduit une législation connue, comme nous l'avons $\mathrm{vu}$, sous le nom américain.

(2pl) Dopóki piją są ugodowi i o to chodzi. Na zdrowie. W piątek Włochy zyskały nowe prawo umożliwiające pozew zbiorowy (ang. classaction) grupy konsumentów przeciw firmie. Już w tę środę skorzystać z tego zamierza grupa Aduc $(\ldots)^{27}$

[Tant qu'ils boivent, ils sont agréables, et c'est tout. Santé ! Vendredi, l'Italie a adopté une nouvelle loi permettant à un groupe de consommateurs d'intenter une action collective contre une entreprise. Ce mercredi, le groupe Aduc entend en profiter (...)]

Lorsque le dispositif devient une réalité en Pologne, on rappelle qu'il est d'inspiration américaine, d'où l'emploi de l'emprunt direct, comme dans l'exemple 3 ci-dessous :

(3pl) Mowa o pozwach zbiorowych. Nie jest to, rzecz jasna, oryginalny pomysł polskich prawników. Pozew zbiorowy (ang. classaction) sięga swoimi korzeniami do średniowiecznych tradycji anglosaskich ${ }^{28}$.

[Nous parlons de recours collectifs. Il ne s'agit pas, bien sûr, d'une idée originale des juristes polonais. Les recours collectifs (ang. classaction) trouvent leurs racines dans les traditions médiévales anglo-saxonnes.]

Dans l'extrait 4 ci-dessous, le scripteur emploie le polonais comme explication de l'anglicisme, encore une fois dans un contexte de jeux vidéo :

(4pl) mam teraz przynajmniej 6 różnych liczb. Która jest prawdziwa? Zdaje się rozwiązanie zagadki nastąpi wtedy, gdy zainicjuję tzw. classaction, czyli pozew zbiorowy klientów T-mobile o fałszywy marketing ${ }^{29}$.

[J’ai maintenant au moins six numéros différents. Lequel est réel ? Je suppose que la solution du puzzle viendra lorsque je lancerai ce que l'on appelle une classaction, ou une action en justice collective par les clients de T-mobile pour faux marketing.]

Lorsqu'il est question de la forme que prendra le dispositif polonais, les journalistes font référence au prédécesseur américain, comme dans l'exemple 5 ci-dessous :

(5pl) Nasz wiejski ustawodawca [...] zaadoptował na polskim gruncie autorską odmianę class action. Trudno oczywiście dzisiaj przesądzić jak się ona przyjmie i jakie będą jej skutki.

26 Wikipédia donne les équivalents suivants : «Un rootkit ou simplement « kit » (aussi appelé « outil de dissimulation d'activité ", "maliciel furtif », "trousse administrateur pirate »). Elle précise que "Certains fournisseurs de matériels informatiques, tel Sony, les utilisent pour s'assurer du respect des conditions d'utilisation de leurs produits par leurs clients. » https://fr.wikipedia.org/wiki/Rootkit, consulté le 04. 01. 2021.

27 linuxnews.pl.

28 pozewzbiorowy.com.pl.

29 computerworld.pl. 
W polskiej wersji classaction pozywać będą mogli jedynie ci, którzy do grupy pozwanych (min. $10-\mathrm{u}$ ) aktywnie przystąpią ${ }^{30}$.

[Notre législateur de Wiejska [...] a adopté sur le terrain polonais une variante de class action en Pologne. Il est évidemment difficile aujourd'hui de déterminer comment elle sera adoptée et quels seront ses effets. Dans la version polonaise du recours collectif, seuls ceux qui se joignent activement à un groupe de défendeurs (au moins 10) pourront intenter une action en justice.]

En revanche, le corpus Timestamped JSI web, qui couvre la plage de temps postérieure à la période de l'adaptation de la procédure en question en Pologne, à savoir les années 2014-2020, affiche seulement 4 occurrences de class action (et aucune de classaction), deux en relation avec des conflits juridiques américains et deux liés aux contextes polonais. Il est intéressant de noter que dans ces derniers commentaires l'emprunt apparaît sans guillemets, sans glose, sans explications, ce qui prouve une relativement bonne implantation du terme d'abord au sein du droit civil polonais, ensuite au sein de la langue polonaise en général :

(6pl) Ludzie oburzyli się na stwierdzenie polskiego sądu, że smogu w Polsce nie ma. „Będzie to pierwszy pozew tego rodzaju w sprawie smogu. Pojawiają się co prawda indywidualne inicjatywy w tym zakresie w Europie i na świecie, ale nie w formie class action. Jesteśmy po analizach prawnych i na tej podstawie kancelaria przekonana jest o zasadności żądania oraz o dużych szansach na sukces w procesie sądowym" - mówi portalowi polsatnews.pl Radosław Górski ${ }^{31}$.

[Les gens ont été scandalisés par la déclaration du tribunal polonais selon laquelle il n’y a pas de smog en Pologne. "Ce sera le premier procès de ce type dans le cas du smog. Il existe des initiatives individuelles à cet égard en Europe et dans le monde, mais pas sous la forme d'une class action. Nous avons procédé à des analyses juridiques et, sur cette base, le cabinet d'avocats est convaincu que la demande est justifiée et qu'il y a de bonnes chances de succès dans la procédure judiciaire ». - Radosław Górski raconte à polsatnews.pl]

Les deux corpus mentionnés font état de 5438 occurrences de pozew zbiorowy et 194 occurrences de postępowanie grupowe (le corpus Polish web 2012), ensuite de 1568 occurrences de pozew zbiorowy et 45 occurrences de postepowanie grupowe (le corpus Timestamped JSI), deux équivalents polonais de class action fonctionnant comme synonymes dans le système juridique de ce pays. En plus, la plupart des contextes trouvés concernent des affaires judiciaires en Pologne. Dans la plupart aussi, pour ne pas dire dans tous les contextes, l'un de deux termes polonais est suffisant, l'emprunt à l'anglais n’est pas mentionné.

Il convient également d'ajouter qu'en ce qui concerne la presse, il semble que les termes officiels (mis en gras) soient privilégiés. Les articles de presse emploient rarement la terminologie introduite par les directives de l'UE.

ryzykonomia.pl.

gazetaprawna.pl. 
Tableau 4 : Relevés de class action et ses équivalents polonais dans trois corpus

\begin{tabular}{|c|c|c|c|}
\hline & $\begin{array}{l}\text { Polish web } \\
2012\end{array}$ & $\begin{array}{c}\text { Timestamped JSI } \\
\text { web corpus } \\
2014-2016\end{array}$ & $\begin{array}{c}\text { Timestamped JSI } \\
\text { web corpus } \\
2014-2020\end{array}$ \\
\hline Class action & 115 & 0 & 4 \\
\hline Pozew zbiorowy & 5438 & 610 & 1568 \\
\hline Postępowanie grupowe & 194 & 10 & 45 \\
\hline Powództwo przedstawicielskie & 0 & 0 & 6 \\
\hline $\begin{array}{l}\text { Nakaz zaprzestania szkodliwych } \\
\text { praktyk }\end{array}$ & 5 & 0 & 4 \\
\hline Zbiorowe dochodzenie roszczeń & 3 & 0 & 6 \\
\hline Dochodzenie roszczeń konsumenckich & 3 & 0 & 0 \\
\hline $\begin{array}{l}\text { Zbiorowe powództwo } \\
\text { odszkodowawcze }\end{array}$ & 1 & 0 & 0 \\
\hline $\begin{array}{l}\text { Zbiorowe dochodzenie roszczeń } \\
\text { odszkodowawczych }\end{array}$ & 0 & 0 & 0 \\
\hline $\begin{array}{l}\text { Zbiorowe dochodzenie roszczeń } \\
\text { o zaprzestanie bezprawnych praktyk }\end{array}$ & 0 & 0 & 0 \\
\hline Zbiorowe postępowania sq̨dowe & 0 & 0 & 0 \\
\hline Powództwa zbiorowe & 10 & 0 & 0 \\
\hline $\begin{array}{l}\text { Dochodzenie roszczeń w drodze } \\
\text { powództw przedstawicielskich }\end{array}$ & 0 & 0 & 0 \\
\hline
\end{tabular}

La situation du polonais par rapport à action de groupe semble assez différente des langues déjà étudiées : contrairement à la France et à l'Italie, la Pologne a rapidement adopté un dispositif juridique qui a reçu une dénomination motivée. L'emprunt direct est encore employé dans la presse surtout en tant que xénisme, le plus souvent en faisant référence à un procès se déroulant aux États-Unis, concernant éventuellement des clients polonais. On l'emploie encore pour des initiatives proches prises dans d'autres pays, grâce au rôle de l'anglais en tant que langue véhiculaire, ainsi que dans un contexte polonais lorsqu'il s'agit de reconnaitre l'origine juridique de ce dispositif. Les deux équivalents officiels polonais (pozew zbiorowy et postępowanie grupowe) semblent être privilégiés dans la plupart des commentaires ou des articles concernant la procédure en question.

\subsection{La République tchèque et le tchèque}

En droit tchèque, pour des raisons historiques ( $c f$. point 2.1 supra), la réticence du législateur vis-à-vis d'un mécanisme général de recours collectif était jusqu'à maintenant patente. L'absence même d'un terme juridique générique pour désigner cette catégorie de recours est sur ce point révélatrice. Pourtant, l'introduction d'un tel dispositif a été intensivement discutée pendant des années. Il gagne toujours plus en importance lorsqu'il y a un cas dans lequel les droits d'un plus grand nombre de personnes sont concernés. Dans le passé, le débat a été déclenché à la suite des demandes de remboursement 
des frais bancaires perçus comme illicites par le public ou plus récemment avec l'affaire Dieselgate. $^{32}$

En ce moment, il existe un projet de loi sur le recours collectif, qui a été présenté par le gouvernement (le texte du projet et les travaux préparatoires) le 6 mars 2020 et qui fait actuellement l'objet des débats parlementaires. Au moment de la rédaction de cet article, la loi relative à class action n'a encore été adoptée. Cependant, le projet actuel ${ }^{33}$ nous sera très utile pour étudier la terminologie du dispositif en question dans la langue tchèque.

En effet, le terme hromadná žaloba, représente l'équivalent privilégié par le milieu juridique tchèque, comme l'atteste notamment la proposition de loi sur le recours collectif, adoptant l'expression hromadná žaloba comme le futur terme juridique, contrairement aux textes européens soutenant désormais l'expression zástupná žaloba, ou, au niveau plus abstrait, kolektivní právní ochrana. Les travaux préparatoires, dont le texte est disponible en ligne sur les pages officielles de l'Assemblé nationale tchèque, expliquent que :

(1tch) Tento termín byl upřednostněn oproti pojmům „reprezentativní žaloba“, „zástupná žaloba“ či „skupinová žaloba“ jakožto jednotlivým typům hromadných žaloby. Důvodem byla jednak skutečnost, že pojem „hromadná žaloba“ je pojmem v českém právním prostředí vžitým a nejčastěji s kolektivním řízením spojovaným, zároveň je to pojem obecný a nadřazený. Zákon přitom obsahuje jak prvky žaloby reprezentativní (zejm. žaluje-li nezisková osoba), tak prvky žaloby skupinové (zejm. žaluje-li člen skupiny). Uvedený pojem konečně do budoucna umožňuje případné změny v koncepci či přidání dalších institutů do zákona ${ }^{34}$. [Ce terme a été préféré aux termes „reprezentativní žaloba“, „zástupná žaloba“ ou „skupinová žaloba“ désignant déjà de différents types de recours collectifs. La raison en est, d'une part, que le terme „hromadná žaloba“ est un bien établi dans le milieu juridique tchèque et le plus souvent associé aux procédures de recours collectif et, d'autre part, qu'il s'agit d'un terme général et hyperonymique. La loi contient à la fois des éléments d'une action représentative (en particulier si l'action est intentée par une personne à but non lucratif) et des éléments d'une action de groupe (en particulier si l'action est intentée par un membre d'un groupe). Enfin, ce terme permet à l'avenir d'apporter d'éventuelles modifications à la conception ou d'ajouter d'autres dispositifs à la loi.]

Dans l'explication concernant l'application de la terminologie, le gouvernement tchèque défend sa décision d'utiliser le terme de hromadná žaloba, contrairement à la législation européenne qui emploie zástupná žaloba, car hromadná žaloba n' exprime que le trait de la pluralité de requérants, tandis qu’une action représentative (zástupná žaloba) met déjà l'accent sur un aspect spécifique procédural (la présence d'une entité représentant les demandeurs) et désigne donc un phénomène plus restreint. En revanche, les termes de hromadná žaloba ou bien de kolektivní žaloba sont probablement, selon Winterová (2008: 20), les termes les plus généraux que l'on utilise en tchèque pour désigner des phénomènes très divers. En soulignant la pluralité de demandeurs, hromadná žaloba

32 https://pravniradce.ihned.cz/c1-65384760-hromadna-zaloba-laka-pravniky-i-politiky-ministerstvo -netusi-jak-na-ni, consulté le 17. 09. 2020.

33 Projet de loi sur le recours collectif, présenté par le gouvernement (texte du projet et les travaux préparatoires), disponible sur : psp.cz, consulté le 17. 09. 2020.

34 psp.cz. 
tchèque paraît lexicalement plus proche de l'action de groupe française que de la nouvelle action représentative européenne. ${ }^{35}$

Bien que la terminologie, par ailleurs flottante et pas ancrée, semble exister en tchèque, la pratique, telle quelle, n'est pas encore reconnue par le droit positif du pays (sauf exceptions isolées). En effet, le projet des travaux législatifs a été lancé, d’après un cabinet d'avocats ${ }^{36}$, avec l'objectif de mettre en place une législation complète inspirée par le phénomène de la class action américaine. Le site souligne que la principale impulsion provenait des réclamations des consommateurs mécontents avec des activités commerciales déloyales ou des comportements illégaux d'entrepreneurs.

En outre, Právní prostor ${ }^{37}$, revue spécialisée dans le domaine juridique, affirme que depuis plusieurs années, on travaille de manière intensive sur la législation concernant le recours collectif. Par ailleurs, la revue utilise le terme de zástupná žaloba en mettant l'adjectif hromadná entre parenthèse, couplant à la fois la nouvelle terminologie européenne et la future terminologie tchèque, tout en soulignant que les deux projets " [évoluaient] en parallèle mais pas uniformément ».

En résumé, nous proposons un schéma (infra) expliquant les rapports entre les différents termes évoqués supra, en soulignant que le mot class action n'apparaît pas dans la législation tchèque et son usage reste limité aux discours de vulgarisation scientifique ou aux textes journalistiques où il renvoie aux affaires des États-Unis.

hromadná žaloba (législation tchèque) - kolektivní právní ochrana (EU) --- hyperonymes

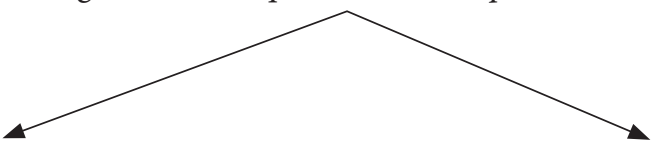

skupinová žaloba

(sorte d'action de groupe)

pluralité de demandeurs zástupná žaloba / reprezentativní žaloba

(sorte d'action de groupe)

introduite par une entité représentative

\subsubsection{Class action dans les corpus de presse tchèque}

Bien que la loi de class action ne soit pas encore adoptée par le système législatif de la République tchèque, nous repérons déjà une terminologie assez variable, celle-ci a été puisée dans les traductions officielles de la communauté ainsi que d'autres textes inclus dans l'outil Treq. Nous avons effectué non seulement une recherche du terme d'origine, class action, mais nous avons également procédé à la recherche via les équivalents français cités supra et le terme polonais pozew zbiorowy. Si les traductions depuis le français proposent notamment des équivalents avec l'adjectif kolektivní (le mot qui apparaît dans la terminologie privilégiée par les textes de l'UE, même si désormais plutôt en association

35 Nous pouvons encore remarquer qu'il existe apparemment une troisième voie - celle de l'anglais des textes européens dont " redress » met l'accent sur la finalité de la procédure et la réparation de l'injustice.

36 Profous legal, https://www.profouslegal.com/index.php/blog/39-hromadna-zaloba-dobry-krok.

37 Právní prostor, https://www.pravniprostor.cz/clanky/procesni-pravo/zpusobilost-kvalifikovanych -subjektu-v-navrhu-smernice-o-zastupnych-hromadnych-zalobach, consulté le 04. 02. 2021. 
avec les intérêts des consommateurs à défendre par les mécanismes étudiés), les traductions via le polonais fournissent les termes de hromadný et de skupinový. Néanmoins, pour la recherche sur la fréquence d'emploi, nous avons utilisé l'ensemble des équivalents retrouvés pendant la période de notre analyse sur le sujet, résumé par le tableau 4 . Ce dernier comprend, par ailleurs comme pour l'étude en français, le nombre d'occurrences dans les trois corpus étudiés : (1) Anopress, base journalistique cumulative qui relève les occurrences dans la presse tchèque depuis 1995, (2) le deuxième corpus se limite aux années 2014-2016 et (3) le dernier corpus indique le plus la situation actuelle en couvrant les années 2017-2020. En outre, étant donné que les archives de presse Anopress permettent de trier les attestations d'après la date, nous avons également incluses dans le tableau une case de la première attestation d'après Anopress.

Tableau 5 : Relevés de class action et ses équivalents tchèques dans trois corpus

\begin{tabular}{|c|c|c|c|c|}
\hline & Anopress & $\begin{array}{c}\text { Première } \\
\text { attestation dans } \\
\text { Anopress }\end{array}$ & $\begin{array}{c}\text { Timestamped JSI } \\
\text { web corpus } \\
2014-2016\end{array}$ & $\begin{array}{c}\text { Timestamped JSI } \\
\text { web corpus } \\
2017-2020\end{array}$ \\
\hline Class action & 704 & 1998 & 4 & 0 \\
\hline Collective redress & 16 & 2008 & 0 & 0 \\
\hline Hromadná soudní pre & 1 & 2013 & 0 & 0 \\
\hline Hromadná žaloba & 13015 & 1995 & 37 & 83 \\
\hline Hromadné ř́zení & 573 & 2003 & 0 & 0 \\
\hline Kolektivní domáhání práv & 0 & - & 0 & 0 \\
\hline $\begin{array}{l}\text { Kolektivní domáhání se } \\
\text { práv }\end{array}$ & 1 & 2008 & 0 & 0 \\
\hline Kolektivní náhrada & 7 & 2018 & 0 & 0 \\
\hline Kolektivní náhrada škody & 5 & 2018 & 0 & 0 \\
\hline Kolektivní náprava & 2 & 2008 & 0 & 0 \\
\hline $\begin{array}{l}\text { Kolektivní nástroje } \\
\text { ochrany }\end{array}$ & 1 & 2018 & 0 & 1 \\
\hline Kolektivní odškodnění & 75 & 1996 & 0 & 0 \\
\hline Kolektivní odvolání & 5 & 2006 & 0 & 0 \\
\hline Kolektivní právní ochrana & 26 & 2001 & 0 & 0 \\
\hline Kolektivní stížnost & 249 & 1996 & 3 & 0 \\
\hline Kolektivní vymáhání & 58 & 1997 & 0 & 0 \\
\hline Kolektivní žaloba & 553 & 1996 & 0 & 65 \\
\hline Reprezentativní žaloba & 102 & 1999 & 1 & 0 \\
\hline Skupinová žaloba & 414 & 1997 & 3 & 0 \\
\hline Tř́dní akce & $172 !$ & $1996 !$ & $1 !$ & $3 !$ \\
\hline Zástupná žaloba & 138 & 2008 & 0 & 0 \\
\hline
\end{tabular}


En observant le tableau, nous pouvons constater que le terme hyperonymique privilégié par la législation tchèque hromadná žaloba est le terme le plus répandu dans les trois documents étudiés, et sa datation remonte jusqu'à 1995. Il est intéressant de voir que son synonyme le plus proche, évoqué notamment par la juriste Winterová (2008), kolektivní žaloba affiche 65 résultats, et se trouve ainsi en deuxième position de fréquence dans le corpus actuel de JSI, tandis que dans le corpus Anopress, il est au $4^{\mathrm{e}}$ rang, précédé par hromadné rízení et à notre surprise par class action, ce dernier ayant 4 résultats dans le corpus JSI 2014-2016 et aucune occurrence dans les données les plus actuelles du corpus JSI. Class action représente donc deuxième terme avec le plus d'occurrences dans Anopress, cependant il est majoritairement accompagné de marques métalinguistiques, des guillemets, et se rapporte souvent aux affaires des États-Unis, notamment pour les cas moins récents, $c f$. l'exemple de 1998 infra:

(2tch) Firma se odvolávala proti verdiktu soudce Okly Jonese, který rozhodl, aby se soud zabýval žalobou paní Castanové, zahrnující „podvod, zanedbání povinností a velmi vysoké odškodné“ jako tzv. „class action“, precedenční případ, kdy se bude verdikt týkat rozhodnutí statisíců obdobně postižených osob. Úkolem Starrovy obhajoby bylo zabránit tomu, aby se př́ípad stal «class action», kdy by nárok na odškodné získal každý kuřák i každý bývalý kuřák.

cité via Anopress ${ }^{38}$

[L’entreprise a fait appel du verdict contre le juge Okla Jones, qui a décidé que le tribunal devrait traiter l'action de Mme Castan, comprenant „fraude, négligence aux obligations et indemnisation très élevée“ en tant que soit-disant „class action“, un précédent dont le verdict concernera des décisions de centaines de milliers de personnes touchées de la même manière. L'objectif de la défense de Starr était d'empêcher que l'affaire ne devienne une „class action“, où chaque fumeur et chaque ancien fumeur auraient droit à une indemnisation.]

L'autre terme d'origine étrangère présent dans Anopress, collective redress, n'apparaît qu'en 2008, par ailleurs comme trois d'autres termes : kolektivní domáhání se práv, kolektivní náprava et zástupná žaloba, en évoquant les discussions sur le recours collectif au sein de l'UE, notamment « Green Paper On Consumer Collective Redress ${ }^{39}$. Pour terminer, soulignons que le terme třídní akce, une traduction littérale de class action, n'est utilisé que dans le contexte de l'enseignement en parlant des événements à l'école, d'une classe c'est la raison pour laquelle nous avons accompagné ces chiffres par des points d'exclamation.

\section{Conclusion}

L'évolution de la néologie juridique concernant class action en Pologne et en République tchèque se distingue très nettement de ce qui a été constaté pour le français dans différents pays francophones, tout comme pour l'espagnol en Espagne et l'italien en Italie. Si dans ces dernières langues l'emprunt direct a fini par se spécialiser en tant que

38 Britské listy [en ligne]. 1998 [cit. 2020-09-18].

39 Disponible sur : https://eur-lex.europa.eu/legal-content/en/TXT/?uri=CELEX\%3A52008DC0794, consulté le 15. 10. 2020. 
xénisme (en faisant surtout référence à des procès se déroulant à l'étranger, surtout aux États-Unis), il a très longtemps marqué le journalisme, car dans la presse généraliste, il concurrençait le terme officiel sur son propre terrain. Dans les deux langues slaves qui nous intéressent, la situation terminologique semble bien plus stable, malgré le décalage dans le temps de l'adoption : la Pologne a institué une adaptation de la " class action » avant la France - 2010 au lieu de 2014 - et la République tchèque ne l'a pas encore adoptée dans son arsenal juridique. Malgré cette différence, on constate une évolution comparable dans ces deux langues. Il suffit de parcourir les graphiques des trois langues pour constater que la variation y est moindre qu'en français.

Quant à la langue polonaise, il convient de souligner que les deux termes autochtones officiels, celui de pozew zbiorowy et celui de postępowanie grupowe, semblent solidement enracinés dans le discours aussi bien juridique que journalistique. Nous pouvons noter également une légère préférence pour le premier. D’autres équivalents polonais, en particulier ceux qui s'inscrivent dans la lignée envisagée dans la proposition terminologique de l'UE, commencent à prendre de l'importance tout en renforçant la base de mots utilisés de plus en plus fréquemment dans la description de la procédure légale en question. En revanche, l'emprunt direct continue à être employé en tant que xénisme dans les contextes faisant référence aux affaires juridiques étrangères, en dehors de la Pologne.

Pour ce qui est de la langue tchèque, nous pouvons constater que les termes autochtones semblent s'ancrer dans le discours juridique ainsi que journalistique, tandis que les termes étrangers, les emprunts, ne sont employés qu'en parlant de la situation à l'extérieur du pays, notamment en décrivant certaines affaires des États-Unis connues sous le nom de class action. Pour ce qui est de la terminologie, nous observons deux tendances, l'une qui reflète la terminologie au niveau de l'Union européenne (privilégiant jusque tout récemment l'usage de l'adjectif kolektivní pour qualifier les mécanismes de recours étudiés), l'autre, celle de hromadná žaloba qui domine notamment dans le discours juridique tchèque en tant que terme général désignant toute action en justice de plusieurs personnes. Cette catégorie peut être subdivisé en deux groupes distincts, celui de reprezentitvní žaloba et celui de skupinová žaloba. D’autres équivalents autochtones sont employés pour éviter la répétition, pour expliquer une situation concrète avec d'autres termes ou pour parler de résultat attendu - odškodnění, náhrada škody ("indemnisation »).

En ce qui concerne l'Union européenne, il semblerait que son rôle est avant tout incitatif ; c'est ainsi qu'elle propose des principes qui sont nommés non pas par les noms des différents dispositifs nationaux mais par des hyperonymes comme action représentative aujourd'hui et recours collectif dans le passé récent.

$\mathrm{Au}$-delà de la constatation d'une bonne gestion terminologique pour accompagner une réforme juridique en polonais et en tchèque, on peut noter une recherche de motivation dans le choix des néologismes créés dans la langue nationale. Ces motivations peuvent être de différents ordres. En tchèque, les deux formes les plus fréquemment relevées renvoient pour la première à l'usage de l'Union européenne et l'autre à la terminologie doctrinale qui a inspiré le projet de loi actuel. En polonais, les deux termes privilégiés font référence à la législation nationale. Et en français, on peut estimer que la dénomination belge, action en réparation collective, est mieux motivée qu'action de groupe en France, où le groupe est nécessairement représenté par une association dument constituée et reconnue officiellement. 
Ces réflexions mettent également en lumière les limites de la méthodologie utilisée : si la présente étude rend bien compte de la réception contrastée d'un emprunt direct et de ses nombreux équivalents dans les trois pays concernés, elle se révèle insuffisante pour faire ressortir les distinctions juridiques entre adaptations proches mais néanmoins différentes selon les pays et leur système juridique. Un corpus qui s'appuie sur la presse généraliste ne permet pas de faire les distinctions juridiques qui s'imposent. Il serait toutefois intéressant de poursuivre l'étude, mais dans le cadre d'une réflexion jurilinguistique et à l'aide d'un corpus spécialisé afin d'évaluer l'adéquation des noms donnés à ces dispositifs qui concernent très directement le public.

\title{
BIBLIOGRAPHIE
}

Boutmgharine-Idiassner, N. et Humbley, J. « Adaptation de la class action américaine en Espagne et dans la francophonie ». In García Palacios, J. (2016) : La neología en las lenguas románicas: recursos, estrategias y nuevas orientaciones. Berne : Peter Lang, pp. 135-153.

Boutmgharine-Idiassner, N. et Humbley, J. « Adapter la class action aux sociétés francophones ». In Bernhard, D., Boisseau, M., Gérard, Ch., Grass, Th. et Todirascu, A. (2018) : La néologie en contexte : cultures, situations, textes. Limoges : Lambert-Lucas, pp. 83-96.

Garner, B.A. (1995) : A Dictionary of Modern Legal Usage, 2e edition. New York : Oxford University Press.

Garner, B.A., dir. (2009) : Black's Law Dictionary, 9e édition. St Paul, MN : West.

Humbley, J. "Action de groupe, autrement dit class action à la française ». In Frassi, P. et Tallarico, G. (2017) : Autrement dit : définir, reformuler, gloser. Mélanges en hommage à Pierluigi Ligas. Paris : Hermann, pp. 47-68.

Humbley, J. «Class action all'italiana : raisons d'un double échec ». In Jacquet-Pfau, Ch., Napieralski, A. et Sablayrolles, J.-F. (2018) : Emprunts néologiques et équivalents autochtones : études interlangues. Lodz: Université de Lodz, pp. 35-47. < https://wydawnictwo.uni.lodz.pl/produkt/emprunts-neologiques-et-equivalents -autochtones-etudes-interlangues/>, consulté le 29. 12. 2020.

Winterová, A. (2008) : "Hromadné žaloby (procesualistický pohled) »[online], Bulletin advokacie, 10, pp. 21-27, < http://www.cak.cz/files/2291/BA_08_10.pdf >, consulté le 07. 07. 2020.

\author{
Sitographie \\ https://www.pravniprostor.cz \\ https://www.anopress.cz \\ https://eur-lex.europa.eu \\ https://www.sketchengine.eu \\ https://novyradce.ihned.cz \\ https://www.profouslegal.com \\ https://www.europarl.europa.eu/ \\ https://classaction.pl/ \\ http://isap.sejm.gov.pl/isap.nsf/DocDetails.xsp?id=WDU20100070044 \\ https://www.infor.pl/prawo/w-sadzie/pozew-zbiorowy/236522,Wymogi-pozwu-zbiorowego.html \\ https://www.infor.pl/prawo/w-sadzie/postepowanie-sadowe/236468,Jak-przebiega-postepowanie-grupowe.html \\ https://pl.wikipedia.org/wiki/Pozew_zbiorowy \\ https://prawo.gazetaprawna.pl/artykuly/7451,grupowe-roszczenia-w-polskim-prawie-za-i-przeciw.html \\ https://eur-lex.europa.eu/legal-content/cs/TXT/?uri=CELEX\%3A32020L1828
}

\author{
Anna Bobinska \\ Institut d'Études Romanes, Université de Lodz \\ ul. Pomorska 171/173, 90-236 Lodz, PL \\ anna.bobinska@uni.lodz.pl
}


John Humbley

CLILLAC-ARP EA 3967

Université de Paris

Case 7002, 75205 Paris Cedex 13, FR

humbley@eila.univ-paris-diderot.fr

Radka Mudrochová/ Matúš Hanuliak

Institut d'Études Romanes

Faculté des Lettres, Université Charles de Prague

Nám. Jana Palacha 1/2, 11638 Praha 1, CZ

radka.mudrochova@ff.cuni.cz 